\title{
Pelatihan Pengenalan Teknologi Pembelajaran di Masa Pandemik pada SMA Negeri 3 Semarang
}

\author{
Sri Winarno ${ }^{1}$, Asih Rohmani ${ }^{2}$, Indra Gamayanto ${ }^{3}$, Sendi Novianto ${ }^{4}$, Farrikh Al Zami ${ }^{5}$,Sasono \\ Wibowo $^{6}$ \\ 1,2,3,4,5,6 Fakultas Ilmu Komputer, Universitas Dian Nuswantoro, Semarang \\ E-mail: ${ }^{1}$ sri.winarno@dsn.dinus.ac.id, ${ }^{2}$ asih.rohmani@dsn.dinus.ac.id, \\ 3indra.gamayanto@dsn.ac.id, 4 sendi.novianto@dsn.dinus.ac.id, ${ }^{5}$ alzami@dsn.dinus.ac.id, \\ sasono.wibowo@dsn.dinus.ac.id
}

\begin{abstract}
Abstrak
SMA Negeri 3 Semarang merupakan SMA terbaik di kota semarang, merupakan salah satu SMA yang memiliki siswa/i dan guru yang memiliki kompetensi tinggi. Salah satu faktor penting untuk dapat meningkatkan kompetensi tersebut adalah bekerjasama dengan universitas untuk dapat memberikan pelatihan dan peningkatan ilmu pengetahuan dari semua sisi sebagai contoh: pembelajaran daring/luring, pelatihan dalam bidang teknologi informasi, industri kreatif, social media, manajemen, ketrampilan interpersonal dan bidang-bidang lainnya yang dapat meningkatkan persaingan di era globalisasi. Seperti yang kita ketahui, peningkatan kompetensi pada sumber daya manusia pada saat ini merupakan hal yang sangat penting karena dengan meningkatnya kompetensi maka akan mampu bersaing dengan negara-negara lain secara signifikan. Pada pelatihan ini, pembelajaran di masa pandemik yang merupakan bagian pertama dari pelatihan akan berfokus pada bagaimana pembelajaran daring/luring yang efektif dan efesien dapat meningkatkan kompetensi siswa dan guru. Oleh sebab itu, di masa pandemik ini, kita membutuhkan inovasi dan perubahan yang signifikan dalam menghadapi ini semua. Hasil dari artikel ini adalah sebuah konsep dalam proses belajar dan teknologi apa saja yang dapat digunakan dalam meningkatkan kompetensi, sehingga terdapat keseimbangan antara pengalaman dan pengetahuan, ini adalah dua faktor yang tidak dapat dipisahkan satu sama lain. Di sisi yang lain, kemampuan harus memiliki dasar yang kuat dengan pemahaman yang mendalam mengenai sesuatu
\end{abstract}

Kata kunci: Pendidikan, Teknologi informasi, Pandemik, Inovasi, Proses

\begin{abstract}
SMA Negeri 3 Semarang is the best SMA in the city of Semarang. It is one of the SMAs which has high competency students and teachers. One important factor in being able to increase this competence is to collaborate with universities to be able to provide training and increase in knowledge from all sides. For example, online/offline learning, training in information technology, creative industries, social media, management, interpersonal skills and other fields. -Other fields that can increase competition in the era of globalization. As we know, increasing competence in human resources is currently very important because the increasing competence will compete significantly with other countries. In this training, learning during a pandemik, which is the first part of the training, will focus on how effective and efficient online/offline learning can improve students and teachers' competence. Therefore, in this pandemik, we need significant innovation and change in facing all of this. The result of this article is a concept in the learning process. Technology can improve competence so that there is a balance between experience and knowledge; these are two factors that cannot separate from each other. On the other hand, the ability must have a solid foundation with a deep understanding of something
\end{abstract}

Keywords: Education, Information Technology, Pandemik, Innovation, Process 


\section{PENDAHULUAN}

SMA Negeri 3 Semarang adalah merupakan salah satu SMA terbaik di Kota Semarang. Untuk dapat meningkatkan komptensinya, SMA Negeri 3 Semarang bekerjasama untuk meningkatkan kompetensi siswa/i nya dan guru, dengan mengadakan pelatihan di beberapa bidang seperti teknologi informasi yang meliputi proses belajar mengajar di masa pandemik, social media, industri kreatif, dan bidang-bidang lainnya. Hal ini sangat dibutuhkan agar mampu bersaing dalam menghadapi globalisasi. Hal-hal yang sangat dibutuhkan pengembangan sumber daya manusia berbasis teknologi informasi (Human technology), antara lain: (1) Pemahaman tentang dasar-dasar pembelajaran di masa pandemik sehingga dapat meningkatkan keefektifan dan keefesiensian dalam proses belajar mengajar, (2) Data-data dalam proses belajar mengajar di masa pandemik, (3) Pemahaman tentang tipe-tipe pembelajaran, (4) Bagaimana implementasi proses belajar mengajar di masa pandemik, (5) Bagaimana proses belajar mengajar tepat pada sasaran di masa pendemic. Perubahan, inilah kata yang penting dan sangat kompleks pemahamannya,perubahan itu sendiri memiliki dua ciri utama yaitu: (1) perubahan akibat situasi dan (2) perubahan akibat sesuatu. Perubahan akibat situasi adalah sebuah perubahan yang ditimbulkan oleh sebuah kondisi yang tidak terduga dan/atau sebuah kondisi yang berada di luar kebiasaan, sehingga hal ini menuntut kita untuk segera beradaptasi dengan hal tersebut, sedangkan perubahan akibat sesuatu adalah perubahan akibat masa lalu dan hal itu mengakibatkan seseorang kemungkinan akan melindungi dirinya agar tidak terkena hal itu lagi[1],[2]. Pada masa ini, pendidikan berada pada posisi perubahan akibat situasi, oleh sebab itu dibutuhkan inovasi, teknologi dan penerapan berkesinambungan sehingga kompetensi tetap terjaga dan tentunya mutu tetap berada pada kualitas yang tertinggi. Pengembanganpengembangan ini harus terus dilakukan demi mewujudkan sumber daya manusia yang memiliki kompetensi menghadapi globalisasi[3],[4].

Artikel ini menggunakan metode yang sudah pernah dipublikasikan dan penerapannya adalah memberikan pelatihan mengenai pengembangan dan penerapan dari strategi pendidikan dan bagaimana kita dapat meningkatkan kompentensi sumber daya manusia dalam menghadapi masa pandemi. SMA Negeri 3 semarang, merupakan salah satu SMA dan berusaha terus meningkatkan sumber daya manusianya, terutama guru dan siswa-siswanya serta mengadopsi inovasi dan hal-hal baru sehingga akan mampu menghadapi persaingan global yang terjadi pada saat ini. Hasil dari artikel ini adalah konsep proses belajar mengajar dalam menghadapi masa pandemi

\section{METODE}

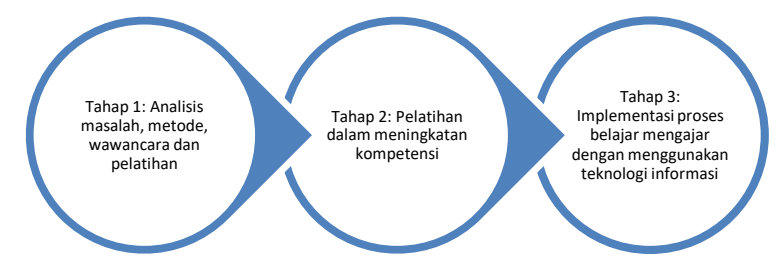

Gambar 1 Proses Penelitian dan Pelatihan di SMA Negeri 3 Semarang

Gambar 1, menjelaskan tahapan penelitian, pengabdian dan pelatihan yang dilakukan di SMA Negeri 3 Semarang. Tahap pertama adalah dilakukan wawancara untuk dapat mengetahui kebutuhan utama dari SMA Negeri 3 Semarang dan kemudian mendiskusikan hal tersebut untuk mencari solusi terbaik. Tahap kedua, mulai mengadakan pelatihan dan penyuluhan dari apa 
yang dibutuhkan dan tahap terakhir adalah model proses belajar yang berguna untuk meningkatkan kompetensi

Metode dan tahapan dalam melakukan pelatihan dan pengabdian, prosesnya adalah sebagai berikut: (1) Mengajarkan bagaimana teknologi dapat diterapkan pada proses belajar mengajar terutama pada masa pandemik; (2) konsep proses belajar mengajar yang lebih efektif dan efesien dalam menghadapi masa pandemik; (3) Pelatihan, pembelajaran dan implementasi, pada tahapan ini siswa SMA Negeri 3 Semarang dan guru akan mampu memahami secara utuh konsep teknologi pembelajaran dan cara mengimplementasikannya.

\section{HASIL DAN PEMBAHASAN}

A. Kegiatan Pengabdian Masyarakat Di SMA Negeri 3 Semarang

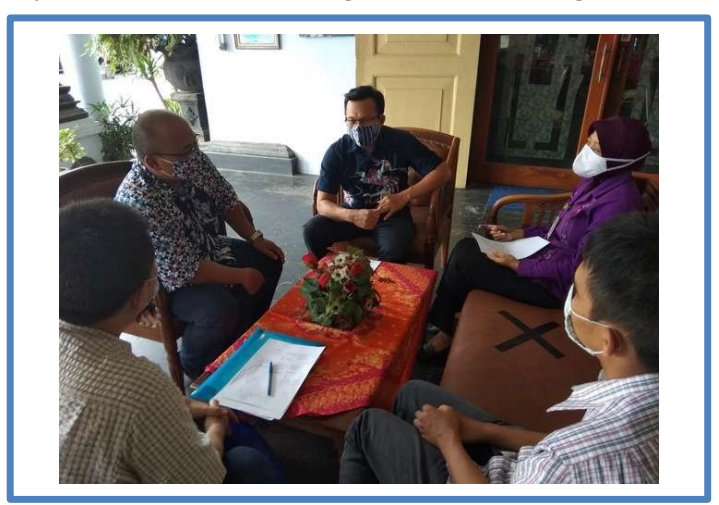

Gambar 2 Proses pertama: wawancara dan mengoleksi data

Pada gambar 3, melakukan wawancara dengan SMA Negeri 3 Semarang, Bpk. Sarojo, S.Pd, M.Pd dan Ibu Fitri. Pada hasil wawancara ini, ditemukan bahwa pada masa pandemik ini dibutuhkan inovasi dalam proses belajar mengajar sehingga kompetensi tetap dapat ditingkatan. SMA Negeri 3 Semarang membutuhkan pengembangan dalam meningkatkan kompetensi siswa/i dan guru-gurunya dalam menghadapi globalisasi, dan di sini permasalahannya adalah: membutuhkan pengetahuan yang lebih luas, sebelum siswa/i tersebut lulus, dengan menambahkan pengetahuan-pengetahuan yang lebih luas dalam bidang teknologi informasi, terutama dalam proses belajar di masa pandemik, bidang social media, industri kreatif, data mining, business online, startup dan sebagainya. 

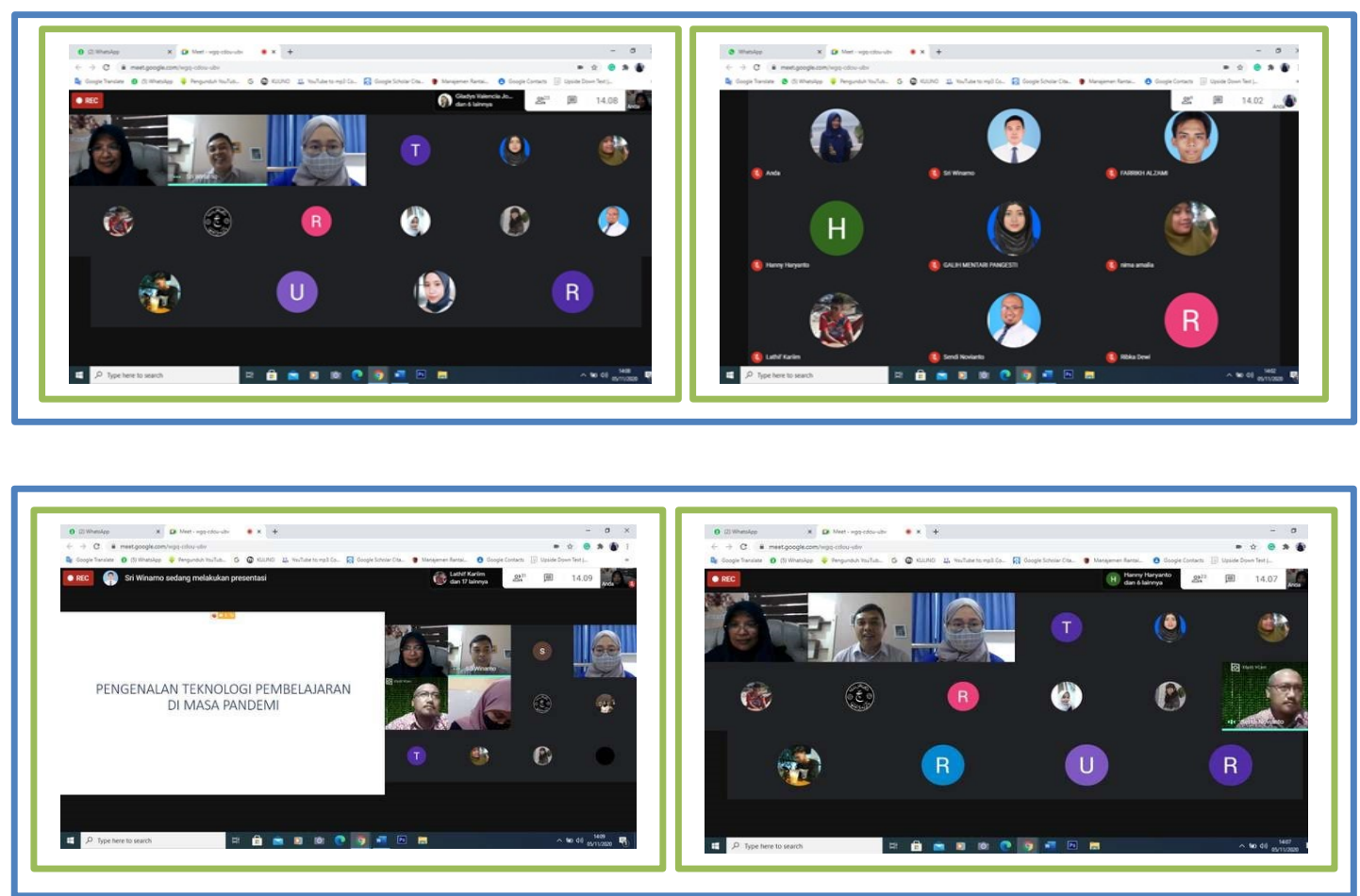

Gambar 3 Proses pelatihan pengenalan teknologi pembelajaran di masa pandemik

Gambar 3, menjelaskan proses yang dilakukan secara online dalam menjelaskan proses belajar mengajar di masa pandemik, oleh Kepala Program studi sistem informasi. Banyak manfaat yang diperoleh pada saat penjelasan ini, sehingga kompetensi tetap dapat ditingkatkan secara maksimum

\section{B. Konten Pelatihan}

Target luaran kegiatan pengabdian ini adalah : (1) Meningkatkan kompetensi siswa/i dan guru dalam proses belajar mengajar, (2) Pemahaman yang mendalam tentang penggunaan teknologi informasi dalam proses belajar, (3) Mampu mengimplementasikan teknologi informasi dalam proses belajar. Metode kegiatan yang dianggap tepat untuk menyelesaikan masalah tersebut adalah pendampingan dan konsultasi berkala untuk penggunaan sarana prasarana IT yang ada., Secara rinci metode yang diterapkan adalah sebagai berikut : (1) Penjelasan proses belajar mengajar di masa pandemik, (2) Penjelasan penggunaan teknologi informasi dalam proses belajar mengajar. Kegiatan pelatihan ini dilaksanakan dalam dua kegiatan terprogram yaitu: Kegiatan 1: Penyiapan Pendampingan- Pelaksanaan kegiatan pendampingan dalam mengajarkan tentang konsep proses belajar di masa pandemik dan dampaknya, Kegiatan 2: Pendampingan IT-Pada tahap ini, Tim Pengabdian Masyarakat beserta SMA Negeri 3 Semarang akan belajar cara mengimplementasikan teknologi informasi dalam proses belajar. 


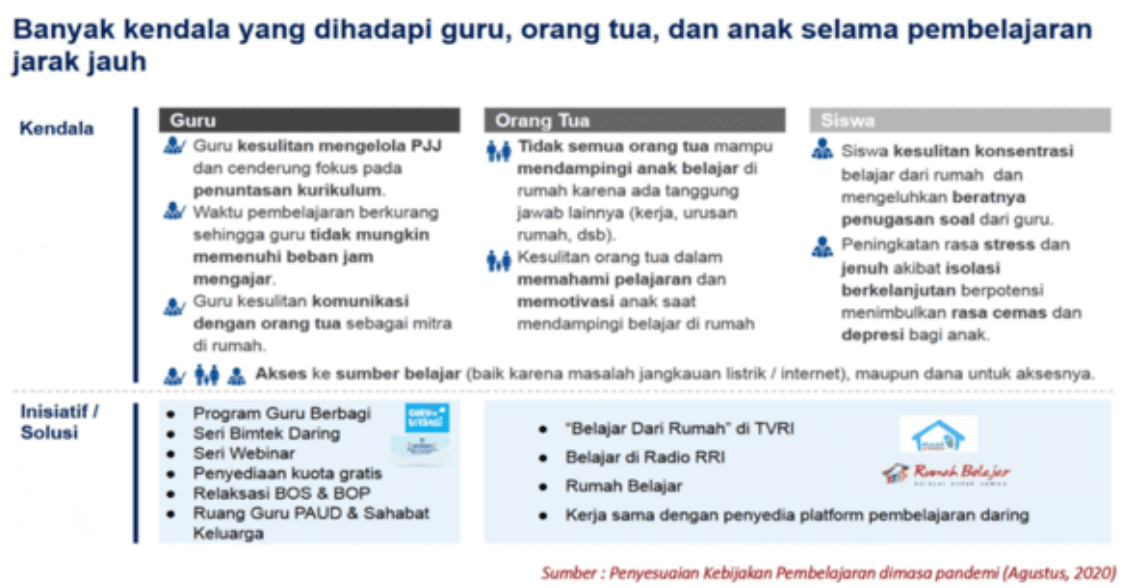

Gambar 4 Guru-orang tua-siswa

Gambar 4, menjelaskan bahwa hubungan antara guru-orang tua-siswa, sangatlah penting dan ini menjadi salah satu faktor penentu dalam meningkatkan kompetensi. Jan Hughes (2007) mengatakan: "Dukungan guru paling baik adalah dukungan yang dianggap sebagai komponen konteks kelas yang memiliki interaksi dengan melibatkan siswa. Di antara factor kontekstual lain dari ruang kelas, hal ini dapat mempengaruhi keaktifan siswa untuk dapat mengembangkan kompetensi siswa. Lebih jauh lagi, hal ini juga konsisten dengan perspektif teori dimana interaksi adalah merupakan hubungan komunikasi yang sangat efektif dalam meningkatkan kompetensi"[5]. Di sisi yang lain, Kathleen M. Minke (2014) mengatakan: "Hubungan orang tua-guru yang sehat memiliki ciri bahwa kebersamaan membangun komitmen, konsistensi, kontinuitas di seluruh sistem Pendidikan[6]. Hal ini akan dapat meningkatkan kepercayaan relasional antara keluarga dan sekolah, serta meningkatkan elemen positif. Jo Tondeur (2019), mengatakan: "guru harus memilki tingkatan tinggi untuk dapat efektif dalam meningkatkan kompetensi"[7]. Shailendra Palvia (2018), mengatakan: "pembelajaran online merupakan cara yang efektif agar proses belajar mengajar tetap berlanjut"[8]

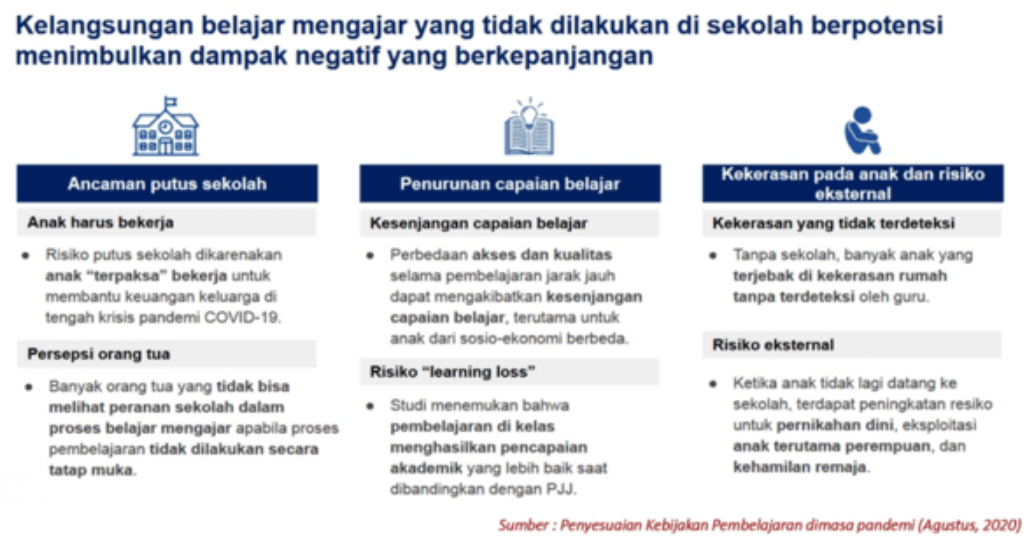

Gambar 5 Ancaman putus sekolah-penurunan capaian belajar-kekerasan pada anak dan resiko eksternal

Gambar 5, menjelaskan proses belajar mengajar yang tidak dilakukan di sekolah memiliki resiko yang cukup besar, dimana terdapat tiga apsek yang harus diatasi segera. Pada 
gambar 6, aspek tersebut telah dijelaskan secara cukup mendetails. Roshni Billaiya (2017), mengatakan: "Siswa adalah merupakan unit yang penting. Oleh sebab itu, kita harus dapat memanfaatkan semua unsur yang dapat menunjang peningkatan kualitas"[9]. Lebih jauh lagi, Muhammad Ropianto (2017), mengatakan: "perkembangan ilmu pengetahuan dan teknologi menuntut kita untuk berinovasi agar dapat menghadapi tantangan global"[10]. Peter Merrotsy (2017), mengatakan: "harus ada perbedaan yang signifikan untuk mengatasi hal ini"[11]. Terakhir, William R. Penuel (2020), mengatakan: "harus ditemukan ide untuk mengatasi dampaknya"[12].

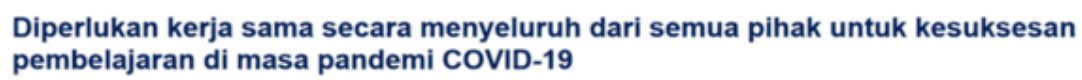
pembelajaran di masa pandemi COVID-19

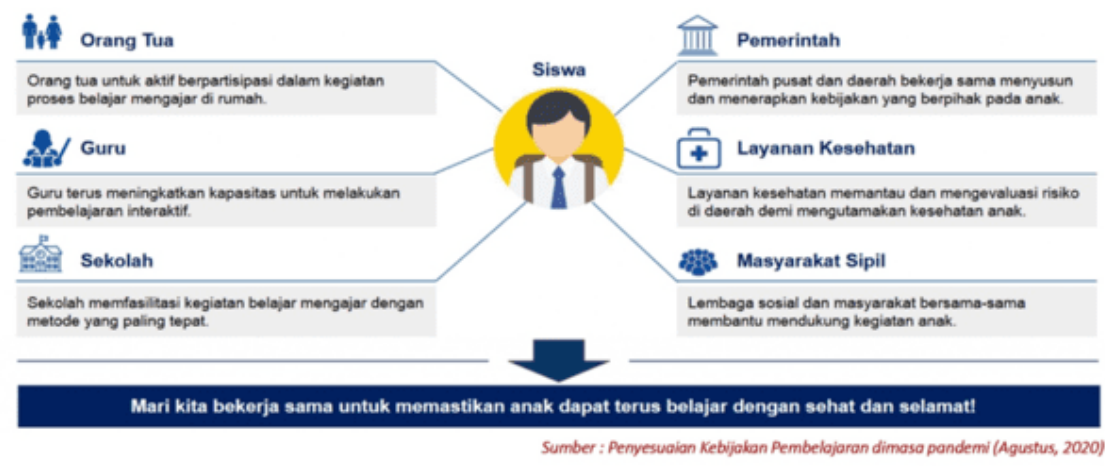

Gambar 6 Kerjasama antara orang tua dan pemerintah

Gambar 6, menjelaskan hubungan antara orang tua dan pemerintah, hal itu terlihat pada gambar 6 serta dijelaskan secara singkat dan jelas. Jan-Eric Gustafsson (2017), mengatakan: "Pendidikan adalah penentu utama mobilitas antargenerasi, dan model teoretis yang berbeda telah dirumuskan untuk menjelaskan determinan dan mekanisme yang melaluinya asal-usul sosial berdampak pada mobilitas dan peluang hidup". Hanan Aldowah (2017), mengatakan: "masa depan pendidikan adalah adaptasi terhadap perubahan"[13].

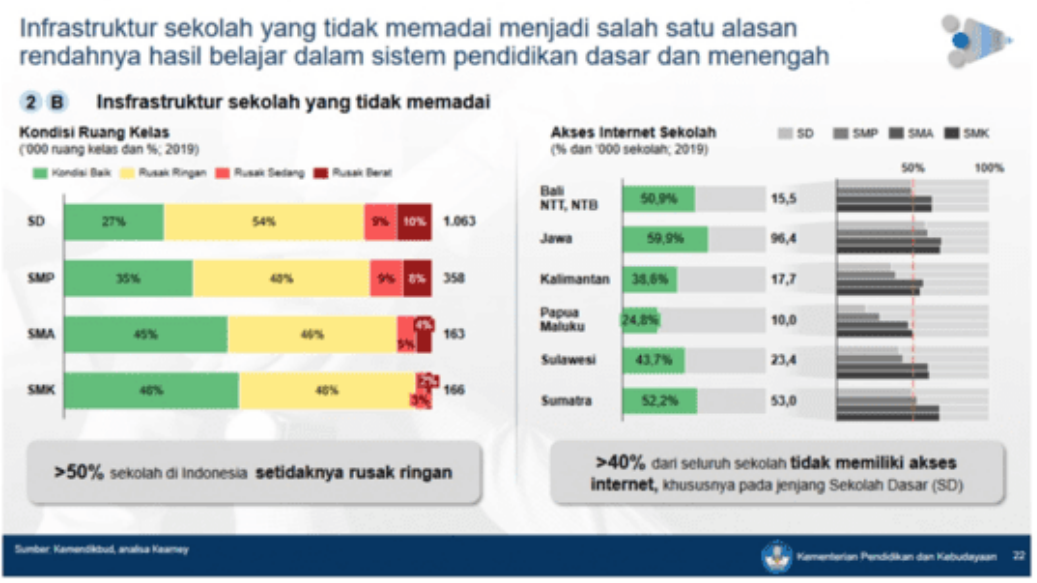

Gambar 7 Infrastruktur sekolah 
Gambar 7, menjelaskan data-data penting mengenai infrastruktur. Felipe Baena (2017), mengatakan: "terdapat tiga pilar transformasi yang perlu diperhatikan antara lain: Pilar didaktikdisesuaikan dengan kelompok ini: kelompok sasaran, tujuan pendidikan dan strategi pembelajaran, Pilar integrasi-meskipun, area manufaktur memiliki frekuensi tertinggi dalam klaster rantai nilai, berbagai pabrik pembelajaran juga melibatkan aktivitas seperti desain, logistik, perencanaan, dan pengendalian produksi, Pilar Teknik-pilar ini mencakup teknologi cluster, tujuan dan strategi Teknik"[14].

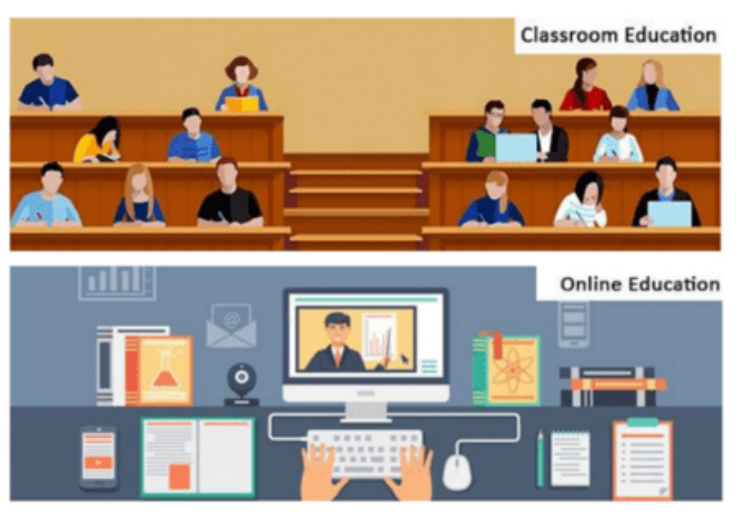

Gambar 8 Classroom Vs Online education

Gambar 8, menjelaskan perbedaan antara kelas regular biasa dan kelas online. Kelas online pada saat ini dibutuhkan agar tetap terjadinya peningkatan kompetensi. Hal ini, tentunya juga memiliki dampak positif yaitu dapat dibangunnya sebuah kebudayaan dan kebiasaan baru yang dapat berdampak efesiensi dan efektifitas setiap orang akan dapat ditingkatkan. Orang akan dapat beradaptasi dan memiliki flesibelitas yang tinggi dalam menghadapi sebuah situasi khususnya pada masa pandemik ini

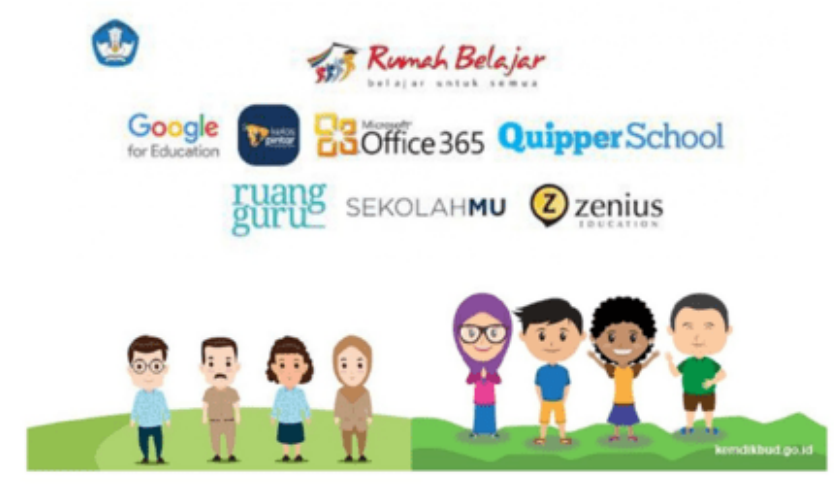

Gambar 9 Rumah belajar

Gambar 9, menjelaskan beberap teknologi yang dapat digunakan dalam proses belajar mengajar, tentunya ini merupakan beberapa teknologi yang efektif agar pembelajaran dapat terus berlangsung dan kompetensi tetap terjaga dalam prosesnya 


\section{KESIMPULAN DAN SARAN}

\subsection{Kesimpulan}

Kesimpulan yang dapat diambil dari hasil pengabdian, pelatihan dan penelitian ini adalah:

Pelaksanaan Pengabdian Masyarakat dilakukan dengan tujuan untuk:

1. Meningkatkan kemampuan dan pemahaman siswa/i dan guru dalam bidang proses belajar di masa pandemik

2. Mampu mengimplementasikan proses belajar mengajar di masa pandemik

3. Mampu mengimplementasikan teknologi informasi untuk proses belajar mengajar

\subsection{Saran}

Kegiatan pengabdian kepada masyarakat ini akan dilakukan secara continue, artinya ini adalah pengabdian masyarakat dalam jangka panjang, dimana pelatihan-pelatihan akan terus dilakukan guna meningkatkan komptensi sumber daya manusia di SMA Negeri 3 Semarang.

\section{UCAPAN TERIMA KASIH}

Kami berterima kasih kepada seluruh SMA Negeri 3, atas kesempatan yang telah diberikan dalam membagikan ilmu pengetahuan dan pelatihan yang diberikan untuk dapat meningkatkan kualitas sumber daya manusia. Kami juga ingin berterima kasih kepada pihakpihak yang telah membantu kami dalam memberikan masukan dan informasi yang bermanfaat dalam menyelesaikan penelitian dan pengabdian masyarakat ini.

\section{DAFTAR PUSTAKA}

[1] H. Christian et al., "The Design of Innovative Leadership Systems Inside University Using Disneyland Concepts to Face Globalization," J. Econ. Manag. Sci., vol. 1, no. 1, pp. 192-206, 2018, doi: 10.30560/jems.v1n1p166.

[2] L. Gombash and M. Ed, "Guiding Social Emotional Learning Through Movement and More.” [Online]. Available: https://www.headstartva.org/assets/Health/2020_21/Guiding Childrens Emotional Learning for Virginia Head Start.pdf.

[3] Indra gamayanto, "Pengembangan mentoring management dalam menghasilkan high quality human resource di tingkat universitas dalam menghadapi masyarakat ekonomi asean (mea) dengan menggunakan konsep kiyosaki dan blanchard abcd trust methodshsova," J. Manaj., vol. 13, no. 2, pp. 158-178, 2016, [Online]. Available: https://www.ristekdikti.go.id/strategi-perguruan-tinggi-.

[4] R. Huang, The Chinese Experience in Maintaining Undisrupted Learning in COVID-19 Outbreak. 2020.

[5] J. Hughes and O. M. Kwok, "Influence of student-teacher and parent-teacher relationships on lower achieving readers' engagement and achievement in the primary grades," J. Educ. Psychol., vol. 99, no. 1, pp. 39-51, 2007, doi: 10.1037/00220663.99.1.39.

[6] K. M. Minke, S. M. Sheridan, E. M. Kim, J. H. Ryoo, and N. A. Koziol, "Congruence in parent-teacher relationships: The role of shared perceptions," Elem. Sch. J., vol. 114, no. 4, pp. 527-546, 2014, doi: 10.1086/675637.

[7] J. Tondeur, R. Scherer, E. Baran, F. Siddiq, T. Valtonen, and E. Sointu, "Teacher educators as gatekeepers: Preparing the next generation of teachers for technology integration in education," Br. J. Educ. Technol., vol. 50, no. 3, pp. 1189-1209, 2019, doi: 10.1111/bjet.12748. 
[8] S. Palvia et al., "Online Education: Worldwide Status, Challenges, Trends, and Implications," J. Glob. Inf. Technol. Manag., vol. 21, no. 4, pp. 233-241, 2018, doi: 10.1080/1097198X.2018.1542262.

[9] R. Billaiya, S. Malaiya, and K. S. Parihar, "Impact of socio economic trends on students in quality education system," Int. J. Soc. Sci. Humanit., vol. 1, no. 1, pp. 16-20, 2017, doi: 10.29332/ijssh.v1n1.10.

[10] M. Ropianto et al., "Optimization of Strategic Planning Organization in the Framework of Achievement Objectives of Education," in Advances in Social Science, Education and Humanities Research (ASSEHR), volume 149 2nd International Conference on Education, Science, and Technology (ICEST 2017) Optimization, 2017, vol. 149, no. Icest, pp. 149-151, doi: 10.2991/icest-17.2017.50.

[11] P. Merrotsy, "Gagné's differentiated model of giftedness and talent in australian education," Australas. J. Gift. Educ., vol. 26, no. 2, pp. 29-42, 2017, doi: 10.21505/ajge.2017.0014.

[12] W. R. Penuel, R. Riedy, M. S. Barber, D. J. Peurach, W. A. LeBouef, and T. Clark, "Principles of Collaborative Education Research With Stakeholders: Toward Requirements for a New Research and Development Infrastructure," Rev. Educ. Res., vol. 90, no. 5, pp. 627-674, 2020, doi: 10.3102/0034654320938126.

[13] H. Aldowah, S. Ul Rehman, S. Ghazal, and I. Naufal Umar, "Internet of Things in Higher Education: A Study on Future Learning," J. Phys. Conf. Ser., vol. 892, no. 1, 2017, doi: 10.1088/1742-6596/892/1/012017.

[14] F. Baena, A. Guarin, J. Mora, J. Sauza, and S. Retat, "Learning Factory: The Path to Industry 4.0," in Procedia Manufacturing, 2017, vol. 9, pp. 73-80, doi: 10.1016/j.promfg.2017.04.022. 